\title{
Impact of maternal pre-pregnancy body mass index on neonatal outcomes: a hospital based study in a tertiary care hospital in Goa
}

\author{
Rini Naik*, Deepa Karmali, Ajit Nagarsenkar, Sneha Mainath, Guruprasad Pednekar
}

Department of Obstetrics and Gynaecology, Goa Medical College, Bambolim, Goa, India

Received: 07 November 2020

Revised: 19 December 2020

Accepted: 29 December 2020

\author{
*Correspondence: \\ Dr. Rini R. Naik, \\ E-mail: rininaik123@gmail.com
}

Copyright: (c) the author(s), publisher and licensee Medip Academy. This is an open-access article distributed under the terms of the Creative Commons Attribution Non-Commercial License, which permits unrestricted non-commercial use, distribution, and reproduction in any medium, provided the original work is properly cited.

\begin{abstract}
Background: Maternal under-nutrition as well as obesity, both are known to have adverse effects on the perinatal outcomes. In developing countries like India wherein the burden of both under-nutrition and obesity is rising, there is a need to spread awareness regarding the need to achieve adequate weight prior to pregnancy. Thus, this study was undertaken to observe effect of maternal pre-pregnancy BMI on neonatal outcomes in Goa Medical College (GMC) during the time period from December 2018- December 2019.

Methods: A hospital based retrospective observational study was conducted wherein the neonatal outcomes of 3940 women delivering in Goa Medical College during the time period of 1 year were studied. All the study participants were divided into five groups depending upon their BMI calculated at the first antenatal visit in the first trimester.

Results: Most of the women in our study were in the normal BMI category $(49.8 \%)$, however a large number were overweight (37.3\%), 3.2\% were obese and $0.1 \%$ were morbidly obese and $9.6 \%$ were underweight. The neonates born to underweight mothers were mostly low birth weight $(66.6 \%)$ while macrosomia was more common in those born to obese $(3.1 \%)$ and morbidly obese $(25 \%)$ women. Neonatal complications like birth asphyxia, respiratory distress syndrome and hypoglycaemia were found in significantly higher proportion in both underweight as well as obese groups. These complications were responsible for a higher NICU admission rate and a higher neonatal mortality observed in both underweight as well obese group of mothers.

Conclusions: Thus in view of the poor neonatal outcomes observed in both extremes of maternal BMI, it is the need of the hour to establish better nutrition programs and educate our women regarding the necessity to achieve adequate pre-pregnancy BMI to improve the pregnancy outcomes.
\end{abstract}

Keywords: Low birth weight, Macrosomia, Maternal obesity, Under nutrition

\section{INTRODUCTION}

India is facing a dual burden of underweight and under nutrition on one hand and overweight and obesity on the other, especially in the urban population secondary to the westernized lifestyle and dietary habits. The data from the National Family Health Survey (NFHS-3) in 2005-06 in India suggests that only $52 \%$ of women had a normal Body Mass Index (BMI). Thirteen percent of women were overweight or obese while $36 \%$ were undernourished. ${ }^{1}$ NFHS-4 survey (2015-16) showed that number of obese people had doubled in the last 10 years. ${ }^{1,2}$ Goa also showed a rise in the percentage of overweight / obese women from $27 \%$ (NFHS-3) in 200506 to $33.5 \%$ (NFHS-4) in $2015-16 . .^{3,4}$

The fetus solely derives its nutrition from the mother, hence its growth and development in- utero depends on the nutritional status of the mother. Maternal undernutrition is found to give birth to small for 
gestational age babies. Maternal obesity on the other hand is associated with fetal macrosomia, prematurity, low apgar score at birth, increased NICU admission rates and increased perinatal mortality. ${ }^{5-9}$ Hence awareness regardingthese outcomes and preconceptional counselling is essential among our women.

Thus this study was undertaken with the aim of studying the effect of maternal pre-pregnancy BMI on neonatal outcomes in Goa Medical College (GMC) during the time period of 1 year (December 2018- December 2019).

\section{METHODS}

A retrospective observational study was conducted in Goa Medical College, in which neonatal outcomes of 3940 women who delivered during the time period of 1 year (December 2018- December 2019) were studied after obtaining an informed consent from the study participants. The data from the hospital medical records and antenatal follow up sheets of these women which included information on their socio-demographic characteristics, past obstetric and medical histories, obstetric and neonatal outcomes was procured. All women with singleton pregnancies that delivered after 28 weeks of gestation and did not have any medical disorders (like hypertension, diabetes mellitus, chronic renal/ hepatic disease and heart disease) were included in the study. The study commenced after obtaining the hospital ethical committee approval.

Table 1: Groups of study participants based on prepregnancy BMI categories.

\begin{tabular}{|lll|}
\hline Group & Category & BMI $\left(\mathrm{kg} / \mathrm{m}^{2}\right)$ \\
\hline I & Underweight & $\leq 19.9$ \\
\hline II & Normal & $20-24.9$ \\
\hline III & Overweight & $25-29.9$ \\
\hline IV & Obese & $30-34.9$ \\
\hline V & Morbidly obese & $>35$ \\
\hline
\end{tabular}

Gestational age was calculated from the first day of the last menstrual period (LMP) or taken from the dating ultrasound scan that was performed before 20 weeks of pregnancy. The pre-pregnancy BMI was calculated using the formula weight $(\mathrm{kg}) /$ height $(\mathrm{m})^{2}$. The pre-pregnancy weight was measured at the first antenatal visit during the first trimester of pregnancy. Body weight was measured in norms with a standard protocol (barefoot, with light clothes on) using an electronic digital scale with the kilogram mode during each antenatal visit. The study participants were then divided into 5 groups according to their first trimester BMIs as shown in Table 1.

The effect of maternal BMI on the neonatal outcomes was studied in all these BMI groups considering the variables like birth weight, gestation at birth, Apgar score at 1 minute, length, head circumference, need for neonatal resuscitation, NICU Admission, hypoglycaemia, respiratory distress syndrome, meconium aspiration, neonatal sepsis, neonatal death and average length of hospital stay.

The statistical analysis of the data was done using SPSS 22 software and a p-value $<0.05$ was considered as significant.

\section{RESULTS}

A total 3940 women delivering in the Department of Obstetrics and Gynaecology, Goa Medical College during a period of 1 year from December 2018 -2019 were included in the present study after obtaining an informed consent from them.

Depending upon the BMI of the study participants calculated at the first antenatal visit, they were divided into following BMI groups as shown in Table 2.

Table 2: Distribution of study participants into 5 groups depending upon their booking BMI category.

\begin{tabular}{|llll|}
\hline Group & Category & $\begin{array}{l}\text { Number } \\
\text { of cases }\end{array}$ & Percentage \\
\hline I & Underweight & 380 & 9.6 \\
\hline II & Normal BMI & 1959 & 49.8 \\
\hline III & Overweight & 1470 & 37.3 \\
\hline IV & Obese & 127 & 3.2 \\
\hline V & Morbidly obese & 4 & 0.1 \\
\hline
\end{tabular}

As seen in Table 2, most of the study participants were in the normal BMI category $(49.8 \%)$, yet a large number of women were overweight $(37.3 \%)$ and $3.2 \%$ were obese, while $9.6 \%$ were underweight.

Table 3: Distribution of birth weight of neonates born to mothers in the different BMI groups.

\begin{tabular}{|c|c|c|c|c|c|}
\hline \multirow[t]{2}{*}{ Birth weight } & Group I (n=380) & $\begin{array}{l}\text { Group II } \\
(\mathrm{n}=1959)\end{array}$ & $\begin{array}{l}\text { Group III } \\
(\mathrm{n}=1470)\end{array}$ & $\begin{array}{l}\text { Group IV } \\
(\mathrm{n}=127)\end{array}$ & $\begin{array}{l}\text { Group V } \\
(n=4)\end{array}$ \\
\hline & $\mathbf{N}(\%)$ & $\mathbf{N}(\%)$ & $\mathbf{N}(\%)$ & $\mathbf{N}(\%)$ & $\mathbf{N}(\%)$ \\
\hline$<2.5 \mathrm{~kg}$ & $253(66.6)$ & $362(18.5)$ & $210(14.3)$ & $26(20.5)$ & 0 \\
\hline $2.5-3.5 \mathrm{~kg}$ & $127(33.4)$ & $1585(81)$ & $1100(74.8)$ & $40(31.5)$ & $1(25)$ \\
\hline $3.5-3.9 \mathrm{~kg}$ & 0 & $12(0.5)$ & $158(10.7)$ & $57(44.9)$ & $2(50)$ \\
\hline$\geq 4 \mathrm{~kg}$ & 0 & 0 & $2(0.2)$ & $4(3.1)$ & $1(25)$ \\
\hline Mean birth weight & $2.04 \mathrm{~kg}$ & $2.7 \mathrm{~kg}$ & $3.01 \mathrm{~kg}$ & $3.2 \mathrm{~kg}$ & $3.7 \mathrm{~kg}$ \\
\hline
\end{tabular}


Table 4: Gestation at birth of the babies born to mothers in different BMI groups.

\begin{tabular}{|llllll|}
\hline $\begin{array}{l}\text { Gestation at birth } \\
\text { (in weeks) }\end{array}$ & $\begin{array}{l}\text { Group I } \\
(\mathbf{n}=\mathbf{3 8 0})\end{array}$ & $\begin{array}{l}\text { Group II } \\
(\mathbf{n}=\mathbf{1 9 5 9 )}\end{array}$ & $\begin{array}{l}\text { Group III } \\
(\mathbf{n}=\mathbf{1 4 7 0 )}\end{array}$ & $\begin{array}{l}\text { Group IV } \\
(\mathbf{n}=\mathbf{1 2 7})\end{array}$ & $\begin{array}{l}\text { Group V } \\
(\mathbf{n}=\mathbf{4})\end{array}$ \\
\hline $\mathbf{N}(\mathbf{\%})$ & $\mathbf{N}(\mathbf{\%})$ & $\mathbf{N}(\mathbf{\%})$ & $\mathbf{N}(\mathbf{\%})$ & $\mathbf{N}(\mathbf{\%})$ \\
\hline $\mathbf{3 4 - 3 7}$ & $29(7.6)$ & $46(2.3)$ & $31(2.1)$ & $6(4.7)$ & 0 \\
\hline $\mathbf{3 7 - 4 0}$ & $75(19.7)$ & $200(10.3)$ & $81(5.5)$ & $15(11.8)$ & 0 \\
\hline$>\mathbf{4 0}$ & $271(71.3)$ & $1660(84.7)$ & $1324(90.1)$ & $100(78.7)$ & $4(100)$ \\
\hline
\end{tabular}

Table 5: Neonatal complications observed in the different BMI groups.

\begin{tabular}{|c|c|c|c|c|c|c|}
\hline Neonatal complications & $\begin{array}{l}\text { Group I } \\
(\mathbf{n}=355)\end{array}$ & $\begin{array}{l}\text { Group II } \\
(\mathrm{n}=1935)\end{array}$ & $\begin{array}{l}\text { Group III } \\
(\mathrm{n}=\mathbf{1 4 2 8})\end{array}$ & $\begin{array}{l}\text { Group IV } \\
(n=106)\end{array}$ & $\begin{array}{l}\text { Group V } \\
(\mathbf{n}=\mathbf{3})\end{array}$ & \multirow[t]{2}{*}{$P$ value } \\
\hline & $\mathbf{N}(\%)$ & $\mathbf{N}(\%)$ & $\mathbf{N}(\%)$ & $\mathbf{N}(\%)$ & $\mathbf{N}(\%)$ & \\
\hline Low birth weight (LBW) & $253(66.6)$ & $362(18.5)$ & $210(14.3)$ & $26(20.5)$ & 0 & \multirow{11}{*}{0.0000} \\
\hline Preterm LBW & $84(33.2)$ & $226(62.4)$ & $110(52.4)$ & $21(80.7)$ & 0 & \\
\hline IUGR LBW & $169(66.8)$ & $136(37.6)$ & $100(47.6)$ & $5(19.3)$ & 0 & \\
\hline Apgar score at $1 \mathrm{~min}<7$ & $112(29.5)$ & $136(7)$ & $172(12)$ & $48(38)$ & $1(25)$ & \\
\hline $\begin{array}{l}\text { Respiratory distress } \\
\text { syndrome (RDS) }\end{array}$ & $78(22)$ & $54(3)$ & $102(7)$ & $21(20)$ & $1(33.3)$ & \\
\hline Neonatal sepsis & $25(7)$ & $46(2.4)$ & $63(4.4)$ & $32(30.2)$ & 0 & \\
\hline Birth injuries & 0 & $2(0.1)$ & $4(0.3)$ & $5(4.7)$ & 0 & \\
\hline Hypoglycemia & $243(68.4)$ & $132(7)$ & $146(10)$ & $54(51)$ & $2(66.7)$ & \\
\hline Jaundice & $152(43)$ & $246(12.7)$ & $304(21.3)$ & $78(73.5)$ & $2(67)$ & \\
\hline NICU admission & $125(35)$ & $148(7.6)$ & $423(30)$ & $49(46.2)$ & $2(66.7)$ & \\
\hline Neonatal death & $16(4.5)$ & $21(1)$ & $28(2)$ & $8(7.5)$ & 0 & \\
\hline
\end{tabular}

Table 3 above shows the distribution of the birth weight of babies born to the mothers in the different BMI groups. The present study showed a high incidence of macrosomia (i.e. birth weight $>4 \mathrm{~kg}$ ) in neonates born to obese $(3.1 \%)$ and morbidly obese mothers $(25 \%)$. On the other hand, most of the neonates born to underweight mothers $(66.6 \%)$ were low birth weight i.e. weighing $<2.5 \mathrm{~kg}$. Thus there was a statistically significant relationship found between maternal BMI and the birth weight of the newborn ( $\mathrm{p}$ value $=0.0000)$.

As seen in Table 4 above, a significantly high incidence of prematurity (i.e gestation $<37$ weeks) was observed in neonates born to obese mothers $(16.5 \%)$ in comparison with the other BMI groups ( $\mathrm{p}$ value $=0.0000$ ). In the present study, it was observed that most of the post-dated neonates were noted in the obese group of mothers $(4.8 \%)$.

Out of the 3940 women that delivered in Goa Medical College during the study period, 113 women had stillbirths most of which were observed in morbidly obese $(25 \%)$ and obese group $(16.5 \%)$ followed by underweight group of women $(6.6 \%)$. Table 5 below shows the distribution of various neonatal complications observed in the babies of 3827 mothers belonging to the different BMI groups in the study.
Thus we observed that extremes of maternal BMI significantly led to adverse neonatal outcomes. The present study showed that majority of the underweight mothers gave birth to low birth weight neonates $(66.6 \%)$ of which, $66.8 \%$ were secondary to intrauterine growth restriction (IUGR) and $33.2 \%$ were due to premature birth.

Birth asphyxia was identified by a low Apgar score at birth. An Apgar score of less than 7 at 1 minute after birth was observed mostly in the neonates born to obese mothers $(38 \%)$ and also in those born to underweight mothers $(29.5 \%)$. Also the incidence of Respiratory Distress Syndrome (RDS) was high in neonates born to underweight mothers (22\%) as well as obese (20\%) and morbidly obese mothers $(33.3 \%)$.

The neonates born to obese mothers were at high risk for neonatal sepsis $(30.2 \%)$ as compared to the other groups. The present study showed that 5 of the neonates born to obese mothers $(4.7 \%)$ had birth injuries at the time of delivery. Hypoglycaemia was observed in the neonates of mostly underweight $(68.4 \%)$ as well as obese $(51 \%)$ and morbidly obese $(66.7 \%)$ mothers. Neonatal jaundice was more common in neonates born to obese mothers $(73.5 \%)$ as compared to the other groups.

Thus due to all these complications observed in the neonates of mothers with extremes of BMI, admissions to 
the Neonatal intensive care unit (NICU) were highest in the neonates of morbidly obese $(66.7 \%)$ and obese group $(46.2 \%)$ of mothers followed by underweight mothers $(35 \%)$. Also a higher percentage of neonatal deaths were noted in the obese group $(7.5 \%)$ and underweight group $(4.5 \%)$ as compared to the others.

\section{DISCUSSION}

Out of the 3940 women delivering in the Department of Obstetrics and Gynaecology, Goa Medical College during a period of 1 year from December 2018 -2019 ,most of the study participants were in the normal BMI category $(49.8 \%)$, while many of them were overweight $(37.3 \%), 3.2 \%$ were obese and only $9.6 \%$ were underweight. A similar study done in Gujarat showed that $5 \%$ of the women studied were obese while, another study done in Kerala showed that $9 \%$ of the women in their study were obese and $3.6 \%$ were morbidly obese..$^{5,6}$ Bhuyar et al. found that only $1 \%$ of the study population was obese. ${ }^{7}$ Similar studies done outside India on the other hand showed a higher incidence of maternal obesity i.e. $5.6 \%$ in the Middle east and $13.3 \%$ in Spain which was much higher than the present study and other Indian studies. $^{8-10}$ This is probably because of the lifestyle variation i.e. more of a sedentary lifestyle and different dietary habits as well as racial and body stature differences in the other countries.

A significantly higher incidence of macrosomia was observed in neonates born to obese $(3.1 \%)$ and morbidly obese mothers $(25 \%)$ whereas; most of the neonates born to underweight mothers $(66.6 \%)$ were low birth weight in the present study. Similar results were observed in numerous studies done in different parts of the country and the world with increased incidence of low birth weight babies in underweight mothers and macrosomia in obese and morbidly obese mothers. ${ }^{5-10}$

In the present study, prematurity was significantly higher in neonates born to obese mothers $(16.5 \%)$ in comparison with the other BMI groups. Similarly a higher incidence of preterm birth was observed in obese mothers in other studies done by Bhuyar et al $(33.3 \%)$ in Maharashtra and Shaukat $(12.17 \%)$ in Qatar. ${ }^{7,9}$ The increased incidence of premature deliveries in obese mothers may be due to increased incidence of pre-eclampsia, eclampsia and antepartum haemorrhage occurring due to maternal obesity.

Although the present study showed that most of the postdated neonates were born to the obese mothers $(4.8 \%)$, it was not a statistically significant finding which was also observed by Bhuyar et al. ${ }^{7}$

Most of the underweight mothers in the present study delivered low birth weight neonates $(66.6 \%)$ due to intrauterine growth restriction (IUGR) and premature birth which was also observed in other similar studies done in India and other parts of the world. .10 $^{5-10}$
A low Apgar score at 1 minute of birth was found mostly in the neonates born to obese mothers $(38 \%)$ and also in those born to underweight mothers $(29.5 \%)$ in the present study. Thus, a higher incidence of Respiratory Distress Syndrome (RDS) was observed in neonates born to underweight mothers $(22 \%)$ as well as obese $(20 \%)$ and morbidly obese mothers $(33.3 \%)$. Similarly other studies also showed low apgar scores and increased need for neonatal resuscitation in underweight as well as obese group of mothers. ${ }^{5-10}$

The present study showed that the neonates born to obese mothers were at high risk for neonatal sepsis (30.2\%) as compared to the other groups. The increased incidence of preterm labour and pre-labour rupture of membranes in obese mothers probably was responsible for the neonatal sepsis noted in this group. Kumar et al. from Kerala found neonatal sepsis as a major cause of death in neonates born to obese mothers. ${ }^{6}$

It was observed that 5 of the neonates born to obese mothers $(4.7 \%)$ had birth injuries at the time of delivery. This is probably because of higher number of instrumental deliveries $(35.6 \%)$ observed in this group of mothers. Similar to the present study, Bhuyar et al. also observed that neonatal jaundice was more common in neonates born to obese mothers as compared to the other groups. $^{7}$

The admissions to the Neonatal intensive care unit (NICU) were found to be the highest in the neonates of morbidly obese $(66.7 \%)$ and obese group $(46.2 \%)$ of mothers followed by underweight mothers (35\%), secondary to the numerous obstetric complications associated in these extremes of maternal BMI groups. This finding was common in other studies done in Kerala, Qatar and Spain. $6,9,10$

The present study showed a higher percentage of neonatal deaths in the obese group $(7.5 \%)$ and underweight group $(4.5 \%)$ as compared to the others. Kumar et al observed perinatal deaths more in the underweight category due to low birth weight and perinatal asphyxia. ${ }^{6}$ Melchor et al. from Spain on the other hand found higher neonatal mortality $(0.27 \%)$ in obese mothers as compared to the normal weight mothers $(0.12 \%){ }^{10}$

Thus extremes of maternal BMI have a significant impact on the neonatal outcomes, as observed in our study. However there were some limitations observed in the present study. The pre-pregnancy maternal BMI was calculated in the first trimester at the first visit which is commonly at around 6 weeks and not prior to pregnancy, as most of the women in our country do not visit a gynaecologist pre-conceptionally. Also these women do not keep a record of their weight. Hence we considered the pre-pregnancy BMI to be the same as that at their first visit at 6 weeks as there is no significant weight gain observed in the first 6 weeks of pregnancy. Also we need to do a follow up to see the catch up growth and weight 
gain in the children born to the mothers with extremes of BMI, in-order to study the effects of maternal BMI on their growth pattern which a longer study and we plan on adding this data in our subsequent research studies.

\section{CONCLUSION}

Thus from the findings observed in the present study, we can conclude that both maternal under nutrition as well as maternal obesity have significant adverse effects on the neonatal outcomes. Underweight mothers mostly give birth to low birth weight infants due to the antenatal complications like anaemia and IUGR associated with their pregnancy. Macrosomia on the other hand is found commonly in neonates born to obese and morbidly obese mothers. The neonates born to both underweight as well as obese mothers are at risk of birth asphyxia, respiratory distress syndrome, hypoglycaemia and thus a higher NICU admission rate. Neonates born to obese mothers have shown higher incidence of birth injuries, neonatal sepsis and neonatal jaundice as compared to those born to mothers with a normal BMI. All these complications observed in the neonates of underweight as well as obese mothers are responsible for the higher neonatal mortality observed in these groups. Thus, a preventive approach needs to be established by the health services in our country to educate women about prenatal nutrition and counsel them to achieve an adequate BMI prior to conception, in order to reduce the perinatal morbidity and mortality associated with the two extremes of maternal BMI.

Funding: No funding sources

Conflict of interest: None declared

Ethical approval: The study was approved by the Institutional Ethics Committee

\section{REFERENCES}

1. International Institute for population sciences. Key Indicators for India from NFHS-3, 2006. Available at www.nfhsindia.org/pdf/India. Accessed on 12 July 2020 .
2. International Institute for population sciences. Key Indicators for India from NFHS-4, 2016. Available at http://rchiips.org/nfhs/nfhs-4Reports/India.pdf. Accessed on 20 August 2020.

3. International Institute for population sciences. Key Indicators for Goa from NFHS-3, 2006.Available at http://rchiips.org/nfhs/nfhs3.shtml. Accessed on 20 August 2020.

4. National Family Health Survey 4, 2015-16, State Fact Sheet- Goa, International Institute for Population Sciences, 2015-16. Available at http://rchiips.org/Nfhs/pdf/NFHS4/GA_FactSheet.pd f. Accessed on 20 August 2020.

5. Bharpoda NY, Leuva BR, Patel U, Patel SG, Srikranthi, Kothari A. Study of the effect of maternal body mass index (BMI) on perinatal outcome. IAIM. 2016;3(2):74-8.

6. Kumar HSA, Chellamma VK. Effect of maternal body mass index on pregnancy outcome. Int J Sci Stud. 2017;4(10):81-4.

7. Bhuyar S, Dharmale N. Effect of maternal body mass index on pregnancy outcomes. Int $\mathbf{J}$ Reprod Contracept Obstet Gynecol. 2018;7:4949-55.

8. Papazian T, Tayeh G, Sibai D, Hout H, Melki I, Khabbaz L. Impact of maternal body mass index and gestational weight gain on neonatal outcomes among healthy Middle- Eastern females. PLoS ONE. 2017;12(7):e0181255.

9. Shaukat S, Nur U. Effect of prepregnancy maternal BMI on adverse pregnancy and neonatal outcomes: results from a retrospective cohort study of a multiethnic population in Qatar. BMJ Open. 2019;9:e029757.

10. Melchor I. Effect of maternal obesity on pregnancy outcomesin women delivering singleton babies: a historical cohort study. J Perinat Med. 2019;47(6):625-30.

Cite this article as: Naik R, Karmali D, Nagarsenkar A, Mainath S, Pednekar G. Impact of maternal prepregnancy body mass index on neonatal outcomes: a hospital based study in a tertiary care hospital in Goa. Int J Reprod Contracept Obstet Gynecol 2021;10:550-4. 